\title{
EMOTIONAL INTELLIGENCE AND JOB SATISFACTION: THE ROLE OF ORGANIZATIONAL LEARNING CAPABILITY
}

\begin{abstract}
Emotional intelligence is becoming one of the most important individual competencies for organizations, which has been theoretically related to organizational performance and to individual variables like job satisfaction. However, some emotionally intelligent people seem to be satisfied with their jobs while others do not. This paper proposes that organizational learning capability plays a significant role in determining the effects of emotional intelligence on job satisfaction. We assess this empirically through the responses of 157 employees from 8 companies in the Spanish ceramic tile sector. Implications of the findings for both academic and practitioners are examined.
\end{abstract}




\section{INTRODUCTION}

According to Goleman (2001, p. 14), emotional intelligence (henceforth EI), at the most general level, refers to the abilities to recognize and regulate emotions in ourselves and in others. Salovey and Mayer (1990, p. 189) understand EI as the ability to monitor one's own and others' emotions, to discriminate between them, and to use the information to guide one's thinking and actions. Publications from Salovey and Mayer (1990) and Goleman (1995) represent the beginning of the EI era in the academic and practitioner contexts, respectively. The construct of EI has received increasing attention in a variety of literature bases, such as competency management (Capaldo et al., 2006). Following this view, EI might be considered as a group of individual competencies essential for organizational performance.

EI can affect an individual's success in an organization (Goleman, 2001). According to popular opinion and workplace testimonials, EI increases performance and productivity (Lam and Kirby, 2002). However, EI literature over-relies on expert opinion, anecdote, and unpublished surveys (Zeidner et al., 2004). The review by these authors underlines the scant, and sometimes highly controversial, empirical evidence used to support the importance of EI in the workplace and recommends that scientific studies be carried out in organizations.

Very little empirical research analyzes the relationship between EI and job satisfaction, which has probably been the most extensively researched work attitude in the organizational behavior literature (Blau, 1999). Zeidner et al. (2004) suggest that EI could be acutely sensitive to possible factors, and, unlike conventional ability, EI may have both positive and negative associations with performance, depending on contextual factors. Bar-On's study (1997) is the only research that reports a modest relationship between total EI scores and job satisfaction. However, this direct positive effect could be due to the sample, comprised of a group of individuals in higher level occupations. Abraham (2000) found that although EI was related to job satisfaction, this was moderated by an environmental characteristic: job control. It is not sufficient to hire emotionally intelligent employees; for them to thrive, the environment must offer autonomy in decision making. In sum, some EI people are satisfied with their jobs while others are not. This might be mediated by certain organizational conditions or characteristics.

In our research we will analyze a particular environmental characteristic: that which facilitates organizational learning. The concept of organizational learning has expanded greatly over the last few years, both in the field of research and among practitioners. One of the main reasons for this growth in importance lies in the new characteristics of the business environment (Dodgson, 
1993; Easterby-Smith et al., 1998). The concept of organizational learning capability (OLC) (Dibella et al., 1996; Goh and Richards, 1997; Hult and Ferrell, 1997; Yeung et al., 1999) emphasizes the importance of the facilitating factors for organizational learning. Goh and Richards (1997, p. 577) define it as the organizational and managerial characteristics that facilitate organizational learning or allow an organization to learn. Five facilitating factors appear to explain OLC (Chiva et al., 2007): experimentation, risk taking, interaction with the external environment, dialogue and participative decision making.

The aim of this research is to analyze whether more emotionally intelligent people tend to derive greater satisfaction from their jobs, through certain working conditions that facilitate organizational learning. Understanding the conditions under which EI influences job satisfaction will help to determine its potential importance for organizations, specifically through the lenses of the new competencies management literature. On the other hand, it will relate important and new concepts being used by organizations, such as competencies management and organizational learning.

This introduction is followed by a brief review of the concepts of EI and OLC, and their relationships with job satisfaction. Secondly, we explain the methodology followed in this research. We then expose the results and close by outlining the implications and limits of our study and proposals for future research. 


\section{CONCEPTUAL BACKGROUND AND HYPOTHESES}

\section{Emotional Intelligence}

EI is a relatively new and growing field of research, essential for many areas such as business and management. Peter Salovey and John Mayer first proposed their theory of EI in 1990. Over the intervening decades, theorists have generated several definitions of EI. Based on an analysis of the literature, Zeidner et al. (2004) consider that there are two models of EI: mental ability models and mixed models.

Mental ability models focus on aptitude for processing affective information, in which EI is viewed as a well defined and conceptually related set of cognitive abilities for the processing of emotional information and regulating emotion adaptively. EI is "the ability to monitor one's own and others' emotions, to discriminate between them, and to use the information to guide one's thinking and actions" (Salovey and Mayer, 1990, p. 189). Those who conceptualize EI as a fairly well defined set of emotion-processing skills (e.g. Mayer et al., 1999, 2000) endeavor to assess EI with objective performance tests, such as solving problems or identification of emotions in pictures.

Mixed models conceptualize EI as a diverse construct, including aspects of personality as well as the ability to perceive, assimilate, understand, and manage emotions. These mixed models include motivational factors and affective dispositions. Bar-On (1997, p. 16), describes EI as "an array of non-cognitive capabilities, competencies, and skills that influence one's ability to succeed in coping with environmental demand and pressures". Goleman $(1998,2001)$ suggests that two domain facets define the competencies associated with EI: ability - awareness versus management of emotion; and target - whether competence relates to self versus others. EI is thus described by four components: self awareness of emotions, social awareness or awareness of emotions in others, management of emotions in self and management of emotions in others.

\section{Organizational Learning Capability}

OLC is defined as the organizational and managerial characteristics or factors that facilitate the organizational learning process or allow an organization to learn (Dibella et al., 1996; Goh and Richards, 1997; Hult and Ferrell, 1997; Yeung et al., 1999).

The importance of the factors that facilitate organizational learning has traditionally been dealt with in the learning organization literature, which mainly focuses on the development of 
normative models for the creation of a learning organization. This literature proposes a variety of facilitating factors of organizational learning (Easterby-Smith and Araujo, 1999). However, research from both organizational learning and the learning organization literatures has suggested factors that facilitate learning (Chiva, 2004). Following a comprehensive literature review, Chiva et al. (2007) identified five essential facilitating factors of organizational learning: experimentation, risk taking, interaction with the external environment, dialogue and participative decision making.

Experimentation can be defined as the degree to which new ideas and suggestions are attended to and dealt with sympathetically. Experimentation is the most heavily supported dimension in the OL literature (Hedberg, 1981; Nevis et al., 1995; Tannembaum, 1997; Weick and Westley, 1996; Ulrich et al., 1993; Goh and Richards, 1997; Pedler et al., 1997). Nevis et al. (1995) consider that experimentation involves trying out new ideas, being curious about how things work, or carrying out changes in work processes.

Risk taking can be understood as the tolerance of ambiguity, uncertainty, and errors. Sitkin (1996, p. 541) goes as far as to state that failure is an essential requirement for effective organizational learning, and to this end, examines the advantages and disadvantages of success and errors.

Interaction with the external environment is defined as the scope of relationships with the external environment. The external environment of an organization is defined as factors that are beyond the organization's direct control of influence. Environmental characteristics play an important role in learning, and their influence on organizational learning has been studied by a number of researchers (Bapuji and Crossan, 2004, p. 407).

Dialogue is defined as a sustained collective inquiry into the processes, assumptions, and certainties that make up everyday experience (Isaacs, 1993, p. 25). Some authors (Isaacs, 1993; Schein, 1993; Dixon, 1997) understand dialogue to be vitally important to organizational learning. Although dialogue is often seen as the process by which individual and organizational learning are linked, Oswick et al. (2000) show that dialogue is what generates both individual and organizational learning, thus creating meaning and comprehension.

Participative decision making refers to the level of influence employees have in the decisionmaking process (Cotton et al., 1988). Organizations implement participative decision making to benefit from the motivational effects of increased employee involvement, job satisfaction and 
organizational commitment (Daniels and Bailey, 1999; Latham et al., 1994; and Witt et al., 2000; Scott-Ladd and Chan, 2004).

\section{Job Satisfaction}

Job satisfaction is normally defined as an employee's affective reactions to a job based on a comparison of desired outcomes and actual outcomes (Cranny et al., 1992). In sum, job satisfaction is the degree to which people like their jobs (Spector, 1997). There are important reasons why we should be concerned with job satisfaction. One of the most important is that job satisfaction can lead to employee behaviors that affect organizational functioning and performance (Rowden, 2002). The situational approach to job satisfaction (e.g. Hackman and Oldman, 1980; Herzberg, 1966) understands it to be mainly influenced by working and organizational conditions.

Job satisfaction can be considered either as a related constellation of attitudes about various aspects or facets of the job or as a global feeling about the job (Spector, 1997). The first, the facet approach, is used to find out what elements of the job produce satisfaction or dissatisfaction. This can be particularly useful for organizations that wish to identify areas of dissatisfaction that they want to improve. The second, the global approach, is used to assess overall job satisfaction in relation to other variables of interest. A single item measure is generally used to assess overall job satisfaction (Wanous et al., 1997). Although the use of a single item measure is often questioned, empirically no validity or reliability appears to be lost (Wanous and Reichers, 1996; Wanous et al., 1997; Ganzach, 1998).

\section{Hypotheses}

Based on the discussion of EI, OLC and job satisfaction in the preceding section, we propose a theoretical model shown in Figure 1. The thesis of our model is that EI has an indirect positive effect on job satisfaction, through OLC. Accordingly, we develop and test three hypotheses representing (a) the relationship between EI and job satisfaction, (b) the relationship between EI and OLC, and (c) the relationship between OLC and job satisfaction. 
Emotional Intelligence and Job Satisfaction. Very few empirical studies have analyzed the relationship between EI and job satisfaction. Bar-On (1997) reports a modest relationship between total EI scores and job satisfaction. Abraham (2000) found that although EI was related to job satisfaction, this was moderated by an environmental characteristic: job control. The direct positive effect that Bar-On (1997) reports might be explained by the sample, which consisted of individuals in higher level occupations: teachers, nurses, and salespersons, where the environmental conditions propitiate their abilities. In sum, when the environmental conditions propitiate the individuals' abilities, they might have higher levels of satisfaction.

Insert Figure 2 about here

This interpretation is consistent with the literature suggesting that people desire environments that fit their characteristics (O'Reilly et al., 1991), and with the goal choice literature, which suggests that the choice of goal depends on ability (Locke and Latham, 1990). Similarly, Ganzach (1998) presents a model of relationships between (rational) intelligence, job complexity and job satisfaction. Intelligence has a direct negative effect and an indirect positive effect, mediated by job complexity, on job satisfaction. Zeidner et al. (2004, p. 382) affirm that qualities of agreeableness such as empathy, altruism, and interpersonal sensitivity are central to conceptions of EI, but these qualities may mitigate against effective performance in jobs requiring ruthlessness or toughness. It follows that research on EI should be acutely sensitive to certain factors, and, unlike conventional ability, EI may have both positive and negative associations with performance, depending on contextual characteristics. Therefore the following hypothesis is set forth.

Hypothesis 1: The relationship between EI and job satisfaction is mediated by OLC.

Emotional Intelligence and Organizational Learning Capability. It is claimed that EI affects several work behaviors, including employee commitment, teamwork, development of talent, innovation, quality of service and customer loyalty (Zeidner et al., 2004: 386). According to Cooper (1997), research demonstrates that people with high levels of EI experience greater career success, build stronger personal relationships or lead more effectively. Zeidner et al. (2004) suggest the following explanations for the above: firstly, more emotionally intelligent individuals presumably succeed in communicating their ideas, goals and intentions in 
interesting and assertive ways (Goleman, 1998); secondly, EI may be related to the social skills needed for teamwork (Mayer and Salovey, 1997); thirdly, organizational leaders with high levels of EI may affect the relationship in the work setting, which, in turn, affects group and individual EI and organizational commitment (Cherniss, 2001). Finally, EI is claimed to influence one's ability to succeed in coping with environmental demands and pressures, clearly an important set of behaviors to harness under stressful work conditions (Bar-On, 1997).

Most of these work conditions represent essential behaviors to cope with organizational aims such as learning, change, or adaptability. In spite of the abovementioned analyses of the effects of EI on certain individual facilitators of OL, no research has been undertaken into whether EI influences the full range of the dimensions of OLC. Furthermore, the OL literature (Antonacopoulou and Gabriel, 2001; Scherer and Tran, 2001, Vince, 2002; Fineman, 2003) has theoretically supported the link between EI and the process of learning. Given the potential impact that EI has on OLC, the following hypothesis is set forth.

Hypothesis 2: EI is positively related to OLC.

Organizational learning capability and Job satisfaction: Most research analyzes the influence of certain job characteristics on job satisfaction. The most influential theory of how job characteristics affect people is Hackman and Oldham's job characteristics theory (Hackman and Oldman, 1976, 1980).

Research suggests that job satisfaction, as a work related outcome, is determined by organizational culture and structure (Egan et al., 2004; Fraser et al., 2002). However, few studies of job satisfaction appear to incorporate any of the five conceptual dimensions that define OLC. In their research into the learning organization culture, Egan et al. (2004) describe some of the most relevant antecedents of job satisfaction linked to organizational learning. Bussing et al. (1999) detect a connection between job satisfaction and employee engagement. According to Kim (2002), participative management that incorporates effective supervisory communication can increase job satisfaction. Wagner and LePine (1999) conducted a metaanalysis and find significant impacts of job participation and work performance on job satisfaction. Daniels and Bailey (1999) conclude that participative decision making increases the level of job satisfaction. Eylon and Bamberger (2000) report that empowerment has a significant impact on job satisfaction. Johnson and McIntey (1998) find that the measures of culture most strongly related to job satisfaction are empowerment, involvement, and recognition. Gaertner (2000) states that leadership behaviors related to inspiring teamwork, challenging tradition or enabling others have been shown to have significant effects on job 
satisfaction. Griffin et al. (2001) report that the extent of teamwork is positively related to perceptions of job autonomy, which in turn affects job satisfaction.

These studies have examined the impacts of some individual dimensions related to OLC. We envisage a positive relationship between OLC and job satisfaction.

Hypothesis 3: There is a positive relationship between OLC and job satisfaction 


\section{METHODS}

\section{Sample and Data Collection Procedure}

We tested our hypotheses within the context of the ceramic tile industry. Ceramic tile production is a globalized industry whose features belong to the scale-intensive and the sciencebased trajectories of Pavitt's taxonomy (Alegre et al., 2004). In the production of ceramic tiles, technological accumulation is mainly generated by (1) the design, building and operation of complex production systems (scale-intensive trajectory) and (2) knowledge, skills and techniques emerging from academic chemistry research (science-based trajectory). Most of the firms belonging to this sector are considered to be SMEs, as they do not exceed an average of 250 workers. Spanish ceramic tile production in 2002 represented almost the half of European Union production. The world's biggest ceramic tile producer is China, followed by Spain and Italy.

The field work was carried out from January to April 2004. With the help of ALICER (Center for Innovation and Technology in Ceramic Industrial Design) technicians, eight Spanish ceramic tile manufacturers were selected. These eight companies were assumed to be representative since they meet the main features of Chiva's Classification (Chiva, 2004). The questionnaire was addressed to the operations workers in each organization. We excluded managers in order to obtain a homogeneous set of respondents who expressed their perception of OLC in their organization.

We received a total of 157 valid questionnaires, which represents $61 \%$ of the study population (see Table 1). Both the number of responses and the response rate can be considered satisfactory (Janssen and Van Yperen, 2004).

We asked operations workers, in company time, to answer the overall job satisfaction and OLC questionnaire with reference to their organization. In order to reinforce confidentiality, no managers were present when the questionnaire was being answered. However, a researcher was constantly on hand to immediately resolve any doubts. At the end of the research, we provided an aggregated report on the results to managers of each of the participating companies.

Insert Table 1 about here 


\section{Measures}

We include the whole questionnaire as an appendix to the paper.

Emotional Intelligence. Those who view EI as encompassing multiple aspects of personal functioning (e.g. Bar-On, 1997; Goleman, 1995) seek to measure EI through self-reporting tests, which are designed to assess beliefs and perceptions about an individual's competencies in specific domains.

Because EI is a complex concept, some scholars are reluctant to measure it with scales. In this vein, Fineman (2004) argues that narratives might better catch a richer picture of emotions in organizations. However, because the aim of this research is to analyze links between concepts, we used measurement scales and statistical analysis to test hypotheses and provide conclusions that could be generalized to other contexts.

Accordingly, we used the Schutte et al. (1998) EI scale, which is a self report, Likert-type scale. It is a 33-item emotions scale that assesses the extent to which individuals perceive, understand, regulate, and harness emotions adaptively. On a 7 -point Likert-type scale $(1=$ strongly disagree, 7 = strongly agree), respondents rate their agreement with such items as "I am aware of my emotions as I experience them" and "I help other people feel better when they are down". The sum of all items constitutes the total scale score, which can range from 33 to 231 (higher scores indicate greater EI). This single factor scale has been successfully validated and utilized in several previous studies (Abraham, 2000; Schutte et al. 2001; Sjöberg, 2001; Carmeli, 2003). For example, Schutte et al. (2001) reported a highly satisfactory internal consistency in the measure of emotional intelligence and found that scores in the emotional intelligence measure were related to some characteristics -e.g. optimism, impulse control- as predicted by theory. Both Sjöberg (2001) and Carmelli (2003) found high Cronbach's alphas (0.86 and 0.90 respectively). We also computed Cronbach's alpha to assess the reliability of the Schutte et al. (1998) EI scale: the alpha for this scale was 0.89.

Global job satisfaction. The measure of global job satisfaction was derived from answers to the question "How much do you like your job?" expressed on a seven-level response scale ranging from "dislike it very much" to "like it very much". A single item to measure job satisfaction is used by Gerhart (1987), Staw and Ross (1985) and Ganzach (1998). The latter explains that although reliance on a single item measure is often questionable, it may provide higher construct validity than a multiple item measure, and no loss in reliability is likely to occur (Wanous and Reichers, 1996; Wanous et al., 1997). 
Organizational Learning Capability. From the concept of OLC adopted in our theoretical review, we used Chiva et al.'s (2007) OLC measurement instrument. The OLC measurement instrument was applied using a 7-point Likert-type scale, where 1 represented total disagreement and 7, total agreement. A pre-test was administered to four technicians from ALICER, to ensure that the translation into Spanish was fully understandable.

We provide a detailed assessment of OLC measurement scale psychometric properties because it is a recent measurement scale (Chiva et al., 2007) and because we use this scale as a secondorder factor, including its five dimensions. These psychometric properties were evaluated by following accepted practice in the literature (Anderson and Gerbing, 1988) and included establishing scale dimensionality, reliability, content validity, convergent validity, and discriminant validity (see Table 3 for means, standard deviations, and factor correlations). To confirm dimensionality of the OLC higher-order construct, we ran second-order CFAs. The loadings of the measurement items on the first-order factors and the loadings of the first-order factors on the second-order factors were all significant. The Comparative Fit Index exceeded the recommended threshold of 0.90 for the measurement model, indicating good model fit and a confirmation of scale dimensionality.

We computed both Cronbach's alpha coefficient and composite reliability to assess scale reliability. Table 2 shows the reliability evaluation for each dimension. The composite reliability values and the Cronbach's alpha coefficients are highly satisfactory, all above 0.7 (Hair et al., 1998; Nunnally, 1978).

Insert Table 2 about here

Content validity was established through personal interviews with knowledgeable industry experts (e.g. ALICER technicians). Furthermore, the generation of the dimensions and the items was well grounded in the literature, and the scale was elaborated in accordance with procedures accepted by the literature (Churchill, 1979; DeVellis, 1991; Spector, 1992).

Discriminant and convergent validity were assessed through confirmatory pairwise analyses. The discriminant validity of the OLC dimensions was ascertained by comparing measurement models in which the correlation between the constructs was estimated with a model where the correlation was constrained to 1 (thereby assuming a single-factor structure). The discriminant 
validity was examined for each pair of constructs at a time (Figure 3). Results show that the model where the correlation is not equal to 1 improves the fit for all pairs of constructs, confirming that the two constructs are distinct from each other, although they may be significantly correlated (Bagozzi et al., 1991).

Convergent validity of the OLC dimensions was assessed by comparing a measurement model in which the correlation between the two constructs was estimated with a model where the correlation was constrained to 0 . Results show significant improvements in the pairwise fits, indicating that the two constructs are indeed related and confirming convergent validity (Table 3). Combining the two tests demonstrates that the two constructs are different, evidencing discriminant validity, although they may be related, evidencing convergent validity (Gatignon et al., 2002).

Insert Table 3 about here

\section{Control Variables}

The target population of our study consisted of operations workers, a very homogeneous set of individuals in the context of the Spanish ceramic tiles industry. Respondents were Spanish male blue-collar workers with at least two years continuous employment in their firm. We controlled for education and age by differentiating two levels of education: basic education and basic education plus occupational training, and four age groups: below 26, from 26 to 35, from 36 to 45 , and above 45 years old. Control variables were designed to maintain respondent anonymity and thus enhance the response rate.

\section{Analyses}

The primary analyses of the data set are based on structural equations modeling. Structural equations models have been developed in a number of academic disciplines to substantiate theory. This approach involves developing measurement models to define constructs and then establishing relationships or structural equations among the constructs. Maximum likelihood is an asymptotic estimator, which means large samples are required for stable, consistent estimates. One common rule-of-thumb on the minimum threshold for implementing SEM and 
for testing measurement scales' psychometric properties is that the sample should surpass 100 subjects (Williams et al., 2004; Spector, 1992). Our sample satisfies this condition.

EQS 5.7 software was used to estimate the models for our research hypotheses. Confirmatory Factor Analysis (CFA) was used to check the goodness of the measurement scales; this method also provides the correlations between factors or dimensions and the construct of interest (Mueller, 1996; p. 125). 


\section{RESULTS}

The theoretical model and the hypotheses are tested using full information robust estimation (McKinney, Kanghyun and Zahedi, 2002). Figure 3 shows the results of the structural equations model. The chi-square statistic for the structural equations model is not significant $(\mathrm{p}=0.053)$, therefore the hypothesis of perfect fit cannot be rejected. Additional relevant fit indices suggest a good overall fit (Seibert et al., 2001; Tippins and Sohi, 2003).

The results show that OLC mediates the relationship between EI and job satisfaction. The mediation model explains a relevant amount of variance in job satisfaction (0.254). The literature conceives job satisfaction as a multifactor concept (Hackman and Oldman, 1976; Warr et al., 1979); indeed, results reveal that EI and OLC only explain a portion of job satisfaction.

Figure 3 shows that there is a positive relationship between EI and OLC $(\mathrm{H} 2: \beta=0.301, \mathrm{t}=$ 3.085). This means that the probability that the effect of EI on OLC is due to chance is less than one percent.

Figure 3 also shows that there is a positive relationship between OLC and job satisfaction (H3: $\beta=0.337, t=4.338$ ). This means that the probability that the effect of OLC on job satisfaction is due to chance is less than one percent.

Therefore, Figure 3 supports hypotheses 2 and 3. These results show that workers with high EI will have a tendency to choose working contexts with a high OLC. Similarly, results also unveil that working contexts with higher OLC will propitiate higher levels of job satisfaction.

Furthermore, the direct relationship between EI and job satisfaction is very low and not significant (H1: $\beta=-0.096, t=-1.161)$; that is, this low effect might be due to chance. Taken together, these points provide evidence that OLC has a mediating effect on the relationship between EI and job satisfaction, confirming hypothesis 1. All in all, results provide support to confirm the research hypotheses. 


\section{DISCUSSION}

Although the concept of EI is based on extensive research evidence, the organizational applications of EI "tend to be based on derivative arguments and largely anecdotal descriptions" (Dulewicz and Higgs 2000; p. 231). Consequently, more validated empirical research is needed. EI is becoming one of the most important individual competencies for organizations, and has been theoretically related to organizational performance and to individual variables like job satisfaction. However, some emotionally intelligent people seem to be satisfied with their jobs while others do not. This paper proposes that OLC plays a significant role in determining the effects of EI on job satisfaction.

The papers aims to analyze the effect of EI on job satisfaction, by taking into consideration OLC. Results suggest that OLC plays a significant role in determining the outcomes of EI. EI should thus be conceptualized as a fit between person and environment; a purely individual attribute does not seem to make sense.

The role of OLC can be explained by the fact that emotionally intelligent individuals tend to work in conditions that propitiate their emotional and social abilities (teamwork, risk taking, dialogue, participation, etc), and consequently they are likely to have higher levels of job satisfaction. OLC might thus be considered as a stimulating working context, where emotionally intelligent people can develop their competencies and achieve satisfaction. Nevertheless, this view does not coincide with certain studies from the critical management literature (e.g. Barker, 1993; Casey, 1999), which consider that these high involvement work practices serve as processes of regulation, control and exploitation of workers. Following from this, EI might have a negative impact on levels of job satisfaction, since only those with well-developed emotional capabilities would be able to recognize and resist covert management attempts to colonize their affective lives through normative control systems ${ }^{1}$.

When seeking to improve employee job satisfaction, practitioners should take into account the link between EI and OLC. Our results support empirical evidence of the importance of a certain contextual situation for managing competencies, specifically EI. Therefore, competencies (Capaldo et al., 2006) need to be managed through a certain contextual, organizational or managerial situation. In order to suggest some implications for human resource management,

\footnotetext{
${ }^{1}$ We wish to thank the anonymous Personnel Review reviewer for suggesting this view.
} 
one might conclude that under certain conditions (OLC), emotionally intelligent people are more likely to be satisfied. However, under other conditions, autocratic, emotionally unintelligent people might also be as satisfied. People who are not satisfied with their jobs might be emotionally intelligent people in autocratic contexts or emotionally unintelligent people in OLC contexts. The most important implication for human resource management is the correlation between people's emotional capability and the organizational context.

Working conditions are normally considered as the major cause of job satisfaction. The situational approach to job satisfaction (e.g. Hackman and Oldman, 1980; Herzberg, 1966) considers that job satisfaction is primarily determined by the characteristics of the work. However, the dispositional approach (Staw et al., 1986) understands affective dispositions to be the prime determinant of job satisfaction. Job satisfaction may be affected by emotion-related personality traits because job satisfaction has been equated with a pleasurable emotional state (Dorman and Dapf, 2001). Others suggest that the effect of personality dispositions on job satisfaction might be mediated by working conditions (Dorman and Dapf, 2001). This research considers job satisfaction as the result of the relationship between people (EI) and their environmental or working conditions (OLC).

Some limitations must be recognized in the present study. First, we administered the questionnaire to workers only, thus performing an employee based survey to obtain a homogeneous set of respondents. This may constitute a limitation, as we do not take into account other stakeholders. Second, the questionnaires were completed by the internal staff from a single industry to control for potential industry effects across organizations. However, this may limit external validity. To assess the generalizability of our findings, future research should test our hypotheses in other industries and with several stakeholders. Third, the sample size limits our conclusions to Spanish ceramic tile companies. Even though the eight companies were selected as representative of the Spanish ceramic tile industry, the number of respondents clearly limits our conclusions from being extended beyond this sector. Fourth, by using measurement scales to assess EI, OLC and job satisfaction we are assuming certain limitations such as subjectivity or truthfulness in the answers. Measurement scales are not perfect measurement instruments and have both advantages and disadvantages (Fineman, 2004; Spector, 1992; Sharma, 1996; Hair et al., 1998).

Finally, we put forward some suggestions for future lines of research that would complement this study and go beyond some of its limitations. To better understand the relationship between EI, OLC and job satisfaction, new studies should be undertaken in other industrial sectors, 
countries and cultures and with a variety of respondents. It would also be interesting to undertake qualitative research to interview those survey participants that clearly did not fit into the proposed relationships for EI, OLC and job satisfaction. 


\section{REFERENCES}

Abraham, R. (2000), "The role of job control as a moderator of emotional dissonance and emotional intelligence - Outcome relationships", The Journal of Psychology, Vol. 134 No. 2, pp. 169-184.

Alegre, J., Lapiedra, R. and Chiva, R. (2004), "Linking operations strategy and product innovation: an empirical study of Spanish ceramic tile producers", Research Policy, Vol. 33, No. 5, pp. 829-839.

Anderson, J.C. and Gerbing, D.W. (1988) "Structural equation modeling in practice: a review and recommended two-step approach", Psychological Bulletin, Vol. 103, No. 3, pp. 411423.

Antonacopoulou, E.P and Gabriel, Y. (2001), "Emotion, learning and organizational change: towards the integration of psychoanalytic and other perspectives", Journal of Organizational Change Management, Vol. 14, No. 5, pp. 435-451.

Bagozzi, R.P., Yi, Y. and Phillips, L.W. (1991), “Assessing construct validity in organizational research”, Administration Science Quarterly, Vol. 36, pp. 421-458.

Bapuji, H., and Crossan, M. (2004), "From raising questions to providing answers: Reviewing organizational learning research”, Management Learning, Vol. 35, No. 4, pp. 397-417.

Barker, J. R. (1993), "Tightening the iron cage: concertive control in self-managing teams", Administrative Science Quarterly, Vol. 38, No. 3, pp. 408-437.

Bar-On, R. (1997), The Emotional Intelligence Inventory (EQ-I): Technical manual. Toronto: Multi-Health Systems.

Blau, G. (1999), "Testing the longitudinal impact of work variables and performance appraisal satisfaction on subsequent overall job satisfaction”, Human Relations, Vol. 52 No. 8, pp. 1099-1113.

Bussing, A. Bissels, T., Fuchs, V. and Perrar, K. (1999), "A dynamic model of work satisfaction: qualitative approaches", Human Relations, Vol. 52 No. 8, pp. 999-1028.

Capaldo, G., Iandoli, L. and Zollo, G. (2006), "A situationalist perspective to competency management”, Human Resource Management, Vol. 45 No. 3, pp. 429-448. 
Carmeli, A. (2003), "The relationship between emotional intelligence and work attitudes, behaviour and outcomes", Journal of Managerial Psychology, Vol. 18, No. 8, pp. 788813.

Casey, C. (1999), “"Come join our family": discipline and integration in corporate organizational culture", Human Relations, Vol. 52, No. 2, pp. 155-178.

Cherniss, C. (2001), "Emotional intelligence and organizational effectiveness". In C. Cherniss and D. Goleman (Eds.), The emotionally intelligent workplace: pp. 3-12. San Francisco: Jossey Bass.

Chiva, R. (2004), “The Facilitating Factors for Organizational Learning in the Ceramic Sector", Human Resource Development International, Vol. 7 No. 2, pp. 233-249.

Chiva, R., Alegre, J. and Lapiedra, R. (2007), "Measuring Organizational Learning Capability among the workforce", International Journal of Manpower, Vol. 28 No. 3, (forthcoming).

Churchill, G.A. (1979), "A paradigm for developing better measures of marketing constructs", Journal of Marketing research, Vol. 17, pp. 64-73.

Cooper, R.K. (1997) “Applying emotional intelligence in the workplace", Training and Development, Vol. 52, pp. 31-33.

Cotton, J.L., Vollrath, D.A., Foggat K.L., Lengnick-Hall, M.L. and Jennings, K.R. (1988), "Employee participation: diverse forms and different outcomes", Academy of Management Review, Vol. 13 No.1, pp. 8-22.

Cranny, C.J., Smith, C.P. and Stone, E.F. (1992), Job satisfaction: how people feel about their jobs and how it affects their performance. San Francisco: New Lexington.

Daniels, K. and Bailey, A. (1999), "Strategy development processes and participation in decision making: predictors of role stressors and job satisfaction", Journal of Applied Management Studies, Vol. 8, No. 1, pp. 27-42.

DeVellis, R. F. (1991), Scale Development: Theory and Applications. Newbury Park, California: Sage Publications.

Dibella, A.J., Nevis, E.C. and Gould, J.M. (1996) "Understanding organizational learning capability", Journal of Management Studies, Vol. 33 No. 3, pp. 361-379. 
Dixon, N. (1997), “The Hallways of Learning”, Organizational Dynamics, Vol. 25 No. 4, pp. 23-34.

Dodgson, M. (1993), “Organizational learning: a review of some literatures”, Organization Science, Vol. 14 No. 3, pp. 375-394.

Dormann, C. and Zapf, D. (2001) "Job satisfaction: a meta analysis of stabilities", Journal of Organizational Behaviour, Vol. 22, pp. 483-504.

Dulewicz, V. and Higgs, M. (2000), "Emotional intelligence: A review and evaluation study", Journal of Managerial Psychology, Vol. 15 No. 4, pp. 341-372.

Easterby-Smith, M. and Araujo, L. (1999), "Organizational learning: Current debates and opportunities". In Easterby-Smith, M., Burgoyne, J.G. and Araujo, L. (Eds.) Organizational learning and the learning organization, pp. 1-21. London: Sage Publications.

Easterby-Smith, M., Snell, R. and Gherardi, S. (1998), "Organizational Learning: Diverging communities of practice?”, Management Learning, Vol. 29, pp. 259-272.

Egan, T.M., Yang, B. and Bartlett, K.R. (2004), “The effects of organizational learning culture and job satisfaction on motivation to transfer learning and turnover intention", Human Resource Development Quarterly, Vol. 15 No. 3, pp. 279-301.

Eylon, D. and Bamberger, P. (2000), "Empowerment cognitions and empowerment acts: recognizing the importance of gender", Group and Organization Management, Vol. 25, pp. 354-373.

Fineman, S. (2003), "Emotionalizing Organizational Learning". In Easterby-Smith, M. and Lyles, M.A. Handbook of Organizational Learning and Knowledge Management. Blackwell Publishing.

Fineman, S. (2004), "Getting the measure of emotion -and the cautionary tale of emotional intelligence", Human Relations, Vol. 57 No 6, pp. 719-740.

Fraser, J., Kick, E. and Kim, B. (2002) "Organizational Culture as contested ground in an era of globalization: worker perceptions and satisfaction in the USPS", Sociological Spectrum, Vol. 22, pp. 445-471. 
Gaertner, S. (2000), "Structural determinants of job satisfaction and organizational commitment in turnover models", Human Resource Management Review, Vol. 9 No 4, pp. 479-493.

Ganzach, Y. (1998), "Intelligence and job satisfaction”, Academy of Management Journal, Vol. 41 No 5, pp. 526-539.

Gatignon, H., Tushman, M.L., Smith, W., and Anderson, P. (2002), "A structural approach to assessing innovation: construct development of innovation locus, type and characteristics", Management Science, 48 (9):1103-1122.

Gerhart, B. (1987), "How important are dispositional factors as determinants of job satisfaction? Implications for job design and other personnel programs", Journal of Applied Psychology, Vol. 72, pp. 366-373.

Goh, S. and Richards, G. (1997), "Benchmarking the learning capability of organizations", European Management Journal, Vol. 15 No. 5, pp. 575-83.

Goleman, D. (1995), Emotional Intelligence, New York: Bantham.

Goleman, D. (1998), Working with Emotional Intelligence, New York: Bantam.

Goleman, D. (2001), "An EI-Based theory of performance". In Cherniss, C. and Goleman, D. (Eds.) The Emotionally Intelligent Workplace. Jossey-Bass: San Francisco.

Griffin, M.A., Patterson, M.G. and West, M.A. (2001) "Job satisfaction and teamwork: the role of supervisor support", Journal of Organizational Behavior, Vol. 22, pp. 537-550.

Hackman J.R. and Oldman, G. R. (1976), "Motivation through the design of work: test of a theory", Organizational behavior and human performance, Vol. 16, pp. 250-279.

Hackman J.R. and Oldman, G. R. (1980), Work redesign, Reading, MA: Addison-Wesley.

Hair, H.F., Anderson R.E., Tatham, R.L. and Black, W.C. (1998), Multivariate Data Analysis, London. Prentice Hall

Hedberg, B. (1981), "How organizations learn and unlearn". In Nystrom, P.C. and Starbuck, W.H. (Eds.) Handbook of Organizational Design. New York: Oxford University Press.

Herzberg, F. (1966), Work and the nature of man. Cleveland: World. 
Hult, G.T.M. and Ferrell, O.C. (1997), "Global Organizational Learning capability in purchasing: construct and measurement", Journal of Business Research, Vol. 40, pp. 97111.

Isaacs, W. (1993), "Dialogue, Collective Thinking, and Organizational Learning", Organizational Dynamics, Vol. 22 No. 2, pp. 24-39.

Janssen, O. and Van Yperen, N.W. (2004) “Employees' goal orientations, the quality of leadermember exchange, and the outcomes of job performance and job satisfaction", Academy of Management Journal, Vol. 47 No. 3, pp. 368-384.

Johnson, J.J. and McIntey C.L. (1998), “Organization culture and climate correlates of job satisfaction", Psychological Reports, Vol. 82, pp. 843-850.

Kim, S. (2002), "Participative management and job satisfaction: lessons for management leadership", Public Administration Review, Vol. 62, pp. 231-241.

Lam, L. T. and Kirby, S. L. (2002), "Is Emotional Intelligence an Advantage? An Exploration of the Impact of Emotional and general intelligence on Individual Performance", The Journal of Social Psychology, Vol. 121 No. 1, pp. 133-143.

Latham, G.P. Winters, D.C. and Locke E.A. (1994), "Cognitive and motivational effects of participation: a mediator study", Journal of Organizational Behaviour, Vol. 1 No. 15, pp. 49-63.

Locke, E. A., and Latham, G. P. (1990), A theory of goal setting and task performance. Englewood Cliffs, NJ: Prentice Hall.

Mayer, J.D. and Salovey, P. (1997). "What is emotional intelligence?" In P. Salovey and D.J. Sluyter (Eds), Emotional development and emotional intelligence: educational implications: pp. 3-31. New York: Basic Books.

Mayer, J.D., Caruso, D., and Salovey, P. (1999), "Emotional intelligence meets traditional standards for an intelligence", Intelligence, Vol. 27, pp. 267-298.

Mayer, J.D., Caruso, D., and Salovey, P. (2000) "Selecting a measure of emotional intelligence: the case of ability scales". In R. Bar-On and J.D.A. (Eds.), The handbook of emotional intelligence: pp. 320-342. San Francisco: Jossey-Bass. 
McKinney, V.; Kanghyun, Y.; Zahedi, F. (2002) "The Measurement of Web-Customer Satisfaction: An Expectation and Disconfirmation Approach", Information Systems Research, Vol. 13 No. 3, pp. 296-315.

Mueller, R.O. (1996), Basic principles of structural equation modeling. An introduction to LISREL and EQS. New York: Springer Texts in Statistics.

Nevis, E., DiBella, A.J. and Gould, J.M. (1995), "Understanding organization learning systems", Sloan Management Review, Vol. 36 No. 2, pp. 73-85.

Nunnally, J. (1978), Psychometric Theory. 2nd Ed. New York: McGraw Hill.

O'Reilly, C., Chatman, J. and Caldwell, D. (1991) "People and organizational culture: A profile comparison approach to assessing person-organization fit", Administrative Science Quarterly, Vol. 34 No. 3, pp. 487-517.

Oswick, C., Anthony, P., Keenoy, T., and Mangham, I.L. (2000), "A dialogic analysis of organizational learning”, Journal of Management Studies, Vol. 37 No. 6, pp. 887-901.

Pedler, M., Burgoyne, J. and Boydell, T (1997), The learning company: A strategy for sustainable development. Maidenhead: McGraw-Hill.

Rowden, R.W. (2002), "The relationship between workplace learning and job satisfaction in U.S. small midsize businesses", Human Resource Development Quarterly, Vol. 13 No. 4, pp. $407-425$.

Salovey, P. and Mayer, J.D. (1990) "Emotional Intelligence", Imagination, Cognition and Personality, Vol. 9 No. 3, pp. 185-211.

Seibert, S.E.; Kraimer, M.L. and Liden, R.C. (2001) “A social Capital theory of career success”, Academy of Management Journal, vol. 44 No. 2, pp. 219-237.

Schein, E.H. (1993), “On Dialogue, Culture, and Organizational Learning”, Organizational Dynamics, Vol. 22 No. 2, pp. 40-51.

Scherer, K.R. and Tran, V. (2001), "Effects of emotion on the process of Organizational Learning”. In Dierkes, M., Ariane, B.A., Child, J. and Nonaka, I. Eds. Handbook of Organizational Learning and Knowledge. New York: Oxford University Press. 
Schutte, N.S., Malouff, J.M., Bobik, C., Coston, T., Greeson, C., Jedlicka, C., Rhodes, E., and Wendorf, G. (2001), „Emotional Intellligence and Interpersonal relations”, The Journal of Social Psychology, Vol. 141 No. 4, pp. 523-536.

Schutte, N.S., Malouff, J.M., Hall, L.E., Haggerty, D.J., Cooper, J.T., Golden, C.J., and Dornheim, L. (1998), “Development and Validation of a measure of EI”, Personality and Individual Differences, Vol. 25, pp. 167-177.

Scott-Ladd, B. and Chan, C.C.A. (2004), "Emotional Intelligence and participation in decisionmaking: strategies for promoting organizational learning and change", Strategic Change, Vol. 13 No. 2, pp. 95-105.

Sitkin, S.B. (1996), "Learning through failure". In Cohen, M. and Sproull, L. (Eds.) Organizational Learning. California: Sage Publications.

Sjöberg, L. (2001), "Emotional Intelligence measured in a highly competitive testing situation". SSE/EFI Working Paper Series in Business Administration N. 2001:13. Stockholm School of Economics.

Spector, P. E. (1997), Job satisfaction. Ca: Sage Publications.

Spector, P.E. (1992), Summated rating scale construction: an introduction. Sage university. California.

Sharma S. (1996). Applied Multivariate Techniques. John Wiley and Sons. New York

Staw, B. M. and Ross, J. (1985), "Stability in the midst of change: A dispositional approach to job attitudes”, Journal of Applied Psychology, Vol. 70, pp. 469480.

Tannenbaum, S.I. (1997), "Enhancing continuous learning: diagnostic findings from multiple companies", Human Resource Management, Vol. 36, pp. 437-52.

Tippins, M.J. and Sohi, R.S. (2003), "IT competency and firm performance: is organizational learning a missing link?", Strategic Management Journal, Vol. 24, pp. 745-761.

Ulrich, D., Jick, T. and Von Glinow, M.A. (1993), "High-impact learning: Building and diffusing learning capability”, Organizational Dynamics, Vol. 22 No 2, pp. 52-79.

Vince, R., Sutcliffe, K. and Olivera, F. (2002) "Organizational Learning: new directions", Bristish Journal of Management, Vol. 13: s1-s6. 
Wagner, J.A. and LePine, J.A. (1999), "Effects of participation on performance and satisfaction: additional meta-analytic evidence", Psychological Reports, Vol. 84, pp. 719-725.

Wanous, J. , Reichers, A. and Hudy, M. (1997), “Overall Job satisfaction: How good are single item measures?" Journal of Applied Psychology, Vol. 82, pp. 247-252.

Wanous, J. P. and Reichers, A. E. (1996) "Estimating the reliability of a single-item measure", Psychological Reports, Vol. 78, pp. 631-634.

Weick, K. E. and Westley, F. (1996) "Organizational learning: affirming an oxymoron". In Clegg, S.R., Hardy, C. and Nord, W.R. (Eds.) Handbook of organizational studies, pp. 440-458. London: Sage.

Williams, L.J., Gavin, M.B. and Hartman, N.S. (2004) "Structural equation modeling methods in strategy research: Applications and issues". In Ketchen, D.J. Jr and Bergh; D.D. (Eds.) Research Methodology in Strategy and Management (vol. 1): pp. 303-346. Oxford: Elsevier.

Witt, L.A., Andrews, M.C and Kacmar K.M. (2000) "The role of participation in decision making in the organizational politics - job satisfaction relationship", Human Relations, Vol. 53 No. 3, pp. 341-358.

Yeung, A. K., Ulrich, D.O., Nason, S.W. and Von Glinow M. (1999), Organizational Learning Capability. New York: Oxford University Press.

Zeidner, M., Matthews, G. and Roberts, R.D. (2004). "Emotional Intelligence in the workplace: a critical review". Applied Psychology: an International Review, Vol. 53 No. 3, pp. 371399. 


\section{FIGURE 1: Theoretical model}

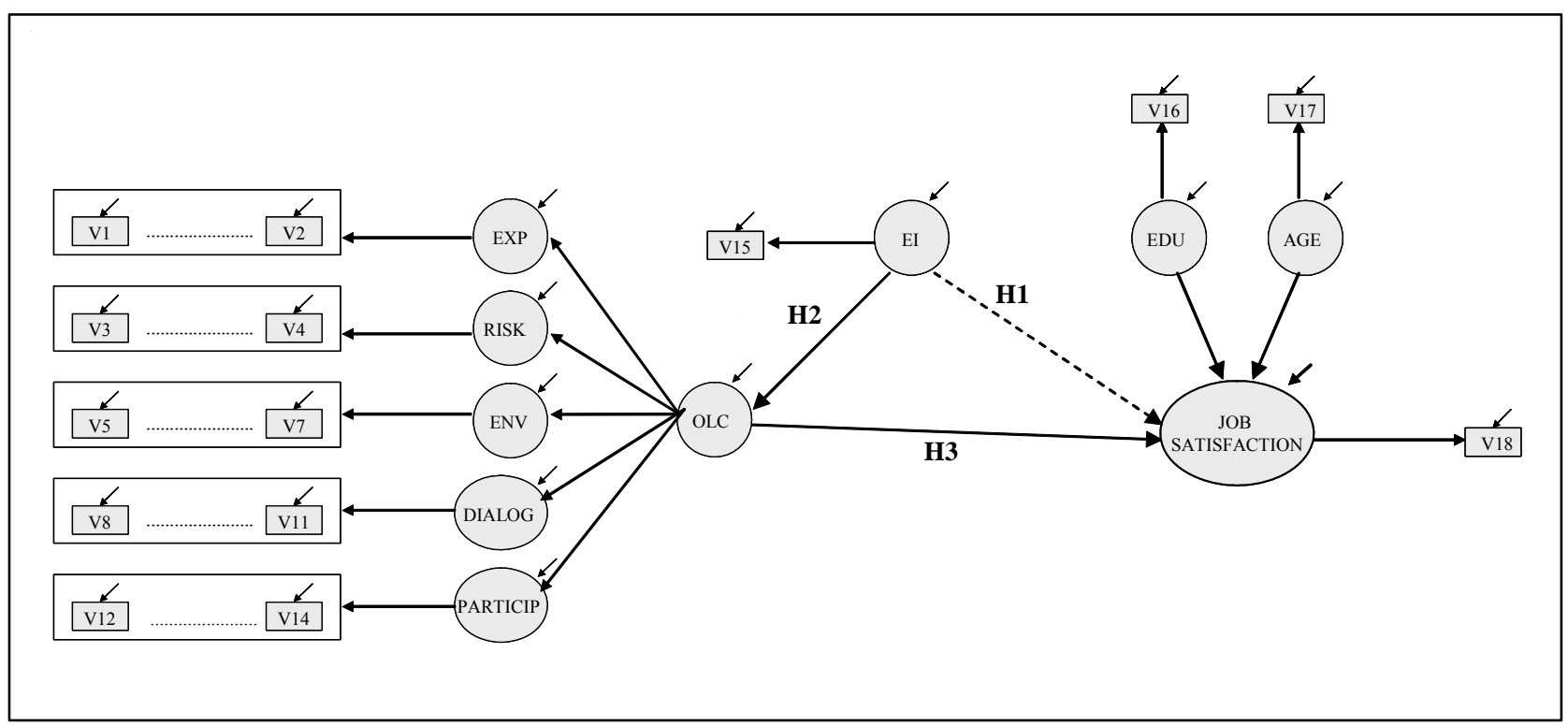

FIGURE 2: Emotional Intelligence and Job Satisfaction

Bar-on (1997)

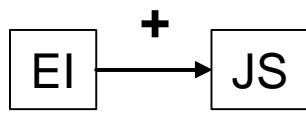

Abraham (2000)

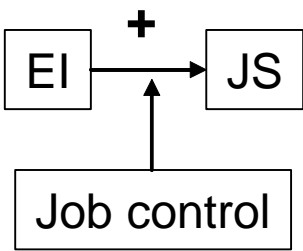

Ganzach (1998)

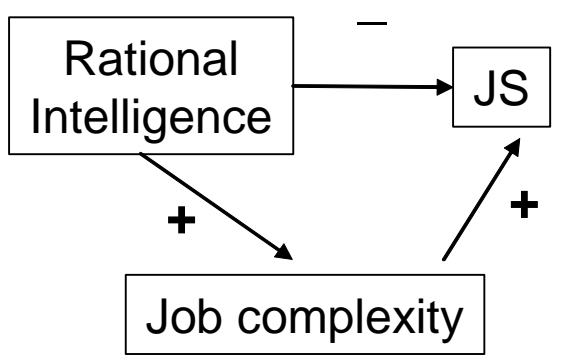


TABLE 1: Response rates

\begin{tabular}{lccccccccc}
\hline & FIRM & FIRM & FIRM & FIRM & FIRM & FIRM & FIRM & FIRM 8 & TOTAL \\
& 1 & 2 & 3 & 4 & 5 & 6 & 7 & & \\
\hline Total number of workers & 25 & 50 & 40 & 20 & 20 & 30 & 35 & 35 & 255 \\
Total number of cases & 25 & 35 & 19 & 14 & 11 & 20 & 15 & 18 & 157 \\
Response rate & $100 \%$ & $70 \%$ & $47 \%$ & $70 \%$ & $55 \%$ & $66 \%$ & $42 \%$ & $51 \%$ & $61 \%$ \\
\hline
\end{tabular}

TABLE 2: Factor correlations, means, standard deviations, composite reliabilities, and Cronbach alphas

\begin{tabular}{|l|c|c|c|c|c|l|l|l|l|}
\hline & Mean & $\begin{array}{l}\text { Standard } \\
\text { deviation }\end{array}$ & $\begin{array}{l}\text { Composit } \\
\text { e } \\
\text { reliability }\end{array}$ & EXP & RISK & ENV & DIALOG & PARTICIP & $\begin{array}{l}\text { JOB } \\
\text { SATISF. }\end{array}$ \\
\hline EXP & 3.69 & 1.54 & 0.78 & $(0.89)$ & & & & & \\
\hline RISK & 3.27 & 1.31 & 0.65 & $\begin{array}{c}0.488^{*} \\
*\end{array}$ & $(0.74)$ & & & & \\
\hline ENV & 3.20 & 1.57 & 0.76 & $\begin{array}{c}0.561^{*} \\
*\end{array}$ & $\begin{array}{c}0.480^{*} \\
*\end{array}$ & $(0.84)$ & & & \\
\hline DIALOG & 3.87 & 1.30 & 0.80 & $\begin{array}{c}0.505^{*} \\
*\end{array}$ & $\begin{array}{c}0.344^{*} \\
*\end{array}$ & $\begin{array}{c}0.470^{*} \\
*\end{array}$ & $(0.86)$ & & \\
\hline PARTICIP & 2.69 & 1.40 & 0.78 & $\begin{array}{c}0.533^{*} \\
*\end{array}$ & $\begin{array}{c}0.481^{*} \\
*\end{array}$ & $\begin{array}{c}0.593^{*} \\
*\end{array}$ & $0.541^{* *}$ & $(0.85)$ & \\
\hline $\begin{array}{l}\text { JOB } \\
\text { SATISF. }\end{array}$ & 4.88 & 1.42 & -- & $\begin{array}{c}0.302^{*} \\
*\end{array}$ & $0.158^{*}$ & $0.162^{*}$ & $0.381^{* *}$ & $0.308^{* *}$ & \\
\hline EI & 153.70 & 22.25 & & $0.180^{*}$ & 0.117 & $380^{* *}$ & 0.109 & $0.267 * *$ & 0.024 \\
\hline
\end{tabular}

All correlation coefficients are statistically significant $(* * \mathrm{p}<0.01 ; * * \mathrm{p}<0.05)$.

Cronbach's alphas are shown on the diagonal.

To calculate the correlation coefficients we worked with the means of the items that make up each dimension 
TABLE 3: Pairwise Confirmatory Analyses for the OLC construct: Estimates of Correlations

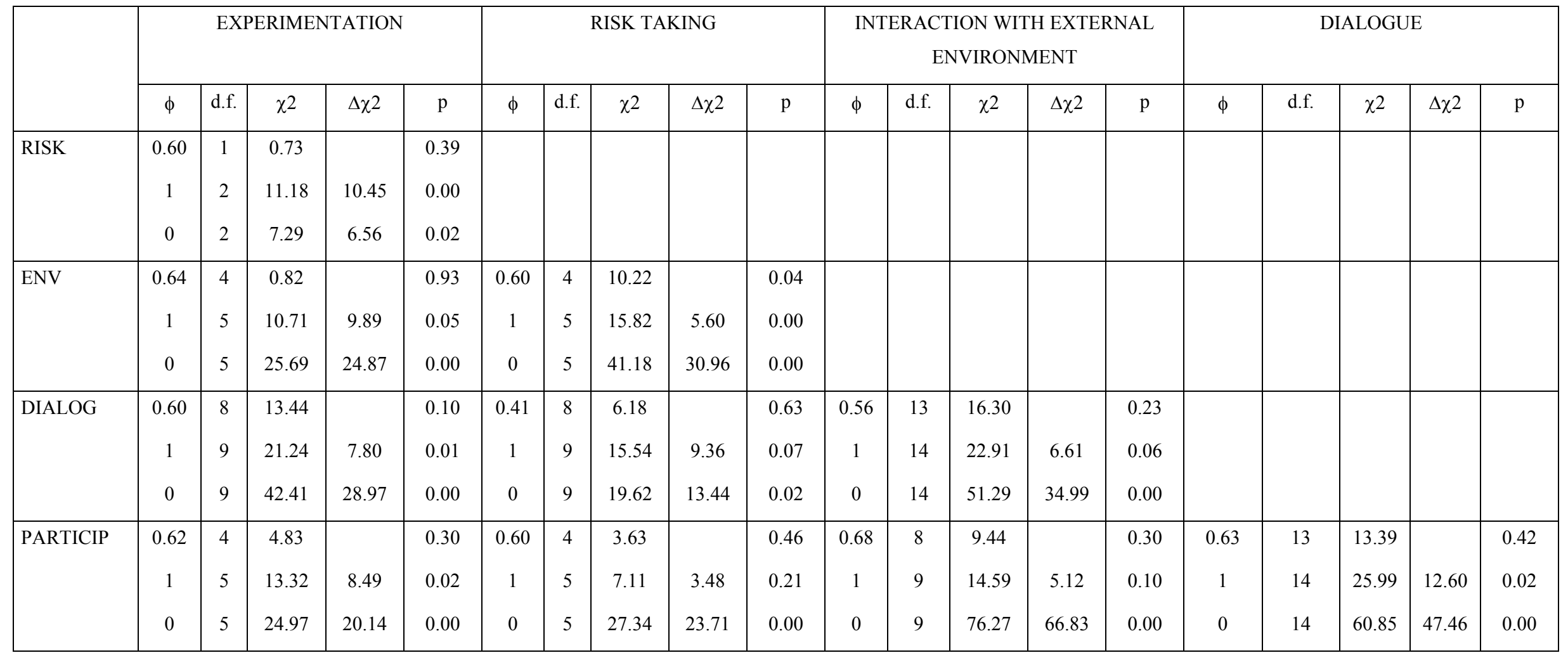


FIGURE 3: Structural Equations Model

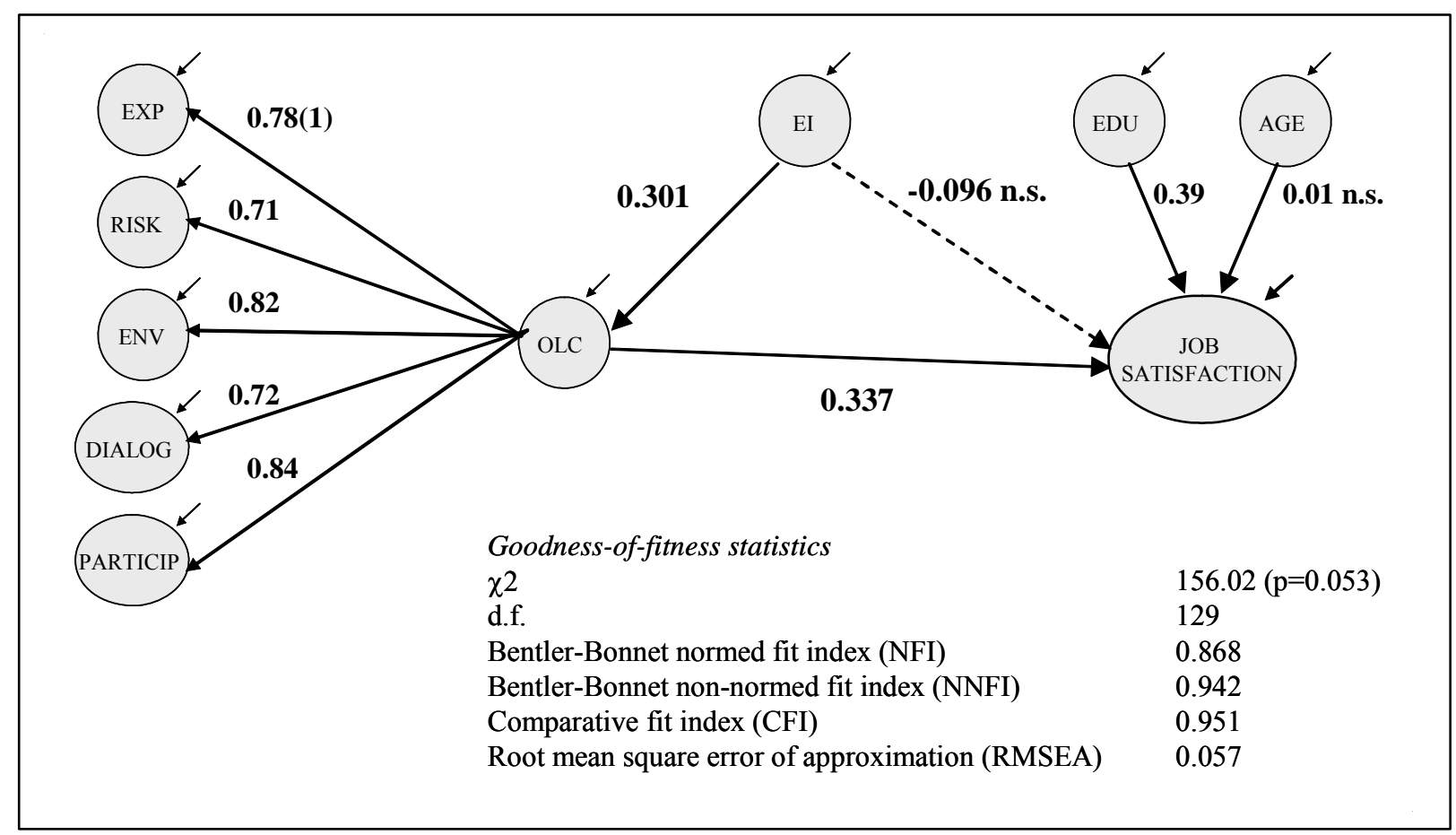

(1) The parameter was equaled to 1 to fix the latent variable scale.

Parameters estimates are standardized with t-values shown in parentheses.

OLC is a second-order factor. For the sake of brevity, only the first-order loadings are shown. The item loadings for these first-order factors were all above 0.69 and significant at $\mathrm{p}<0.01$. 


\section{QUESTIONNAIRE}

\begin{tabular}{|c|c|c|}
\hline Dimension & Item & Source \\
\hline $\begin{array}{l}\text { Organizational } \\
\text { Learning } \\
\text { Capability }\end{array}$ & & $\begin{array}{l}\text { Chiva et al. } \\
(2007)\end{array}$ \\
\hline \multirow{2}{*}{ Experimentation } & 1. People here receive support and encouragement when presenting new ideas & \\
\hline & 2. Initiative often receives a favorable response here so people feel encouraged to generate new ideas & \\
\hline \multirow{2}{*}{ Risk taking } & 3. People are encouraged to take risks in this organization & \\
\hline & 4. People here often venture into unknown territory. & \\
\hline \multirow{3}{*}{$\begin{array}{l}\text { Interaction with } \\
\text { the external } \\
\text { environment }\end{array}$} & $\begin{array}{l}\text { 5. It is part of the work of all staff to collect, bring back, and report information about what is going on outside the } \\
\text { company. }\end{array}$ & \\
\hline & 6. There are systems and procedures for receiving, collating and sharing information from outside the company. & \\
\hline & $\begin{array}{l}\text { 7. People are encouraged to interact with the environment: competitors, customers, technological institutes, } \\
\text { universities, suppliers etc. }\end{array}$ & \\
\hline \multirow{4}{*}{ Dialogue } & 8. Employees are encouraged to communicate. & \\
\hline & 9. There is a free and open communication within my work group & \\
\hline & 10. Managers facilitate communication & \\
\hline & 11. Cross-functional teamwork is a common practice here. & \\
\hline \multirow{3}{*}{$\begin{array}{l}\text { Participative } \\
\text { decision making }\end{array}$} & 12. Managers in this organization frequently involve employees in important decisions & \\
\hline & 13.Policies are significantly influenced by the view of employees & \\
\hline & 14.People feel involved in main company decisions & \\
\hline
\end{tabular}




\begin{tabular}{|c|c|c|}
\hline \multirow[t]{19}{*}{$\begin{array}{l}\text { Emotional } \\
\text { Intelligence }\end{array}$} & & \multirow[t]{19}{*}{\begin{tabular}{|l} 
Schutte et al. \\
(1998)
\end{tabular}} \\
\hline & 1. I know when to speak about my personal problems to others & \\
\hline & 3. I expect that I will do well on most things I try. & \\
\hline & 4. Other people find it easy to confide in me. & \\
\hline & 5. I find it hard to understand the non-verbal messages of other people & \\
\hline & 6. Some of the major events of my life have led me to re-evaluate what is important and not important. & \\
\hline & 7. When my mood changes, I see new possibilities. & \\
\hline & 8. Emotions are one of the things that make my life worth living. & \\
\hline & 9. I am aware of my emotions as I experience them. & \\
\hline & 10. I expect good things to happen. & \\
\hline & 11. I like to share my emotions with others. & \\
\hline & 12. When I experience a positive emotion, I know how to make it last & \\
\hline & 13. I arrange events others enjoy. & \\
\hline & 14. I seek out activities that make me happy. & \\
\hline & 15. I am aware of the non-verbal messages I send to others. & \\
\hline & 16. I present myself in a way that makes a good impression on others. & \\
\hline & 17. When I am in a positive mood, solving problems is easy for me. & \\
\hline & 18. By looking at their facial expressions, I recognize the emotions people are experiencing. & \\
\hline & 19. I know why my emotions change. & \\
\hline
\end{tabular}




\begin{tabular}{|c|c|c|}
\hline & 20. When I am in a positive mood, I am able to come up with new ideas. & \\
\hline & 21. I have control over my emotions. & \\
\hline & 22. I easily recognize my emotions as I experience them. & \\
\hline & 24. I compliment others when they have done something well. & \\
\hline & 25. I am aware of the non-verbal messages other people send. & \\
\hline & 27. When I feel a change in emotions, I tend to come up with new ideas. & \\
\hline & 28. When I am faced with a challenge, I give up because I believe I will fail. & \\
\hline & 29. I know what other people are feeling just by looking at them. & \\
\hline & 30. I help other people feel better when they are down. & \\
\hline Job satisfaction & & Ganzach (1998) \\
\hline & How much do you like your job? & \\
\hline
\end{tabular}

